\title{
Un caso de estudio relacionado con la importancia de educar sobre la seguridad informática a nivel personal y empresarial
}

\section{A case study related to the importance of educating on computer security at a personal and business level}

\author{
URUETA-HINOJOSA, Daniel E.†*”, ALANÍS-CANTÚ, Reynaldo’, TORRES-DEL CARMEN, Felipe \\ de J." y MOTA-CRUZ, Juan E." \\ 'Universidad Politécnica del Estado de Guerrero, Comunidad de Puente Campuzano Carretera Federal Iguala - Taxco K.M. \\ 105 C.P. 40321, Municipio de Taxco de Alarcón, Gro. \\ "Universidad de Guanajuato, Campus Irapuato-Salamanca, Carretera Salamanca - Valle de Santiago km 3.5 + 1.8, C.P. \\ 36885, Comunidad de Palo Blanco, Salamanca, Gto.
}

ID $1^{\text {er }}$ Autor: Daniel E., Urueta-Hinojosa / ORC ID: 0000-0002-8741-6978

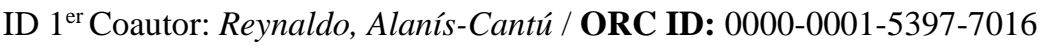

ID $2^{\text {do }}$ Coautor: Felipe de Jesús, Torres-Del Carmen

ID $3^{\text {er }}$ Coautor: Juan Esteban, Mota-Cruz / ORC ID: 0000-0001-6099-9408

DOI: $10.35429 / J I T .2020 .22 .7 .19 .23$

Recibido: Enero 15, 2020; Aceptado Marzo 31, 2020

\begin{abstract}
Resumen
Actualmente, con la masificación de los medios electrónicos de comunicación como celulares y computadoras, la seguridad informática está más vigente que nunca antes; no obstante, el nivel de cultura en la materia de los usuarios está lejos de ser el ideal. El presente trabajo muestra un estudio realizado con dos diferentes tipos de ataques informáticos, uno de forma remota y otro conectando un dispositivo físico a una computadora. Posteriormente se muestra la ejecución y validación de la propuesta en un entorno social; finalmente, las conclusiones obtenidas son mostradas.
\end{abstract}

Seguridad informática, Ingeniería social, Caso de estudio

\begin{abstract}
Currently, with the massification of electronic media such as cell phones and computers, computer security is more in force than ever before; nevertheless, the level of culture in the matter of the users is far from being the ideal. The present work shows a study conducted with two different types of computer attacks, one remotely and the anther one connecting a physical device to a computer. Subsequently, the execution and validation of the proposal in a social environment is shown, finally the conclusions obtained are shown.
\end{abstract}

Computer security, Social engineering, Social study

Citación: URUETA-HINOJOSA, Daniel E., ALANÍS-CANTÚ, Reynaldo, TORRES-DEL CARMEN, Felipe de J. y MOTACRUZ, Juan E. Un caso de estudio relacionado con la importancia de educar sobre la seguridad informática a nivel personal y empresarial. Revista de Tecnologías de la Información. 2020. 7-22:19-23.

\footnotetext{
* Correspondencia del Autor (Correo electrónico: crownirv@ gmail.com)

$\dagger$ Investigador contribuyendo como primer autor.
} 


\section{Introducción}

Con el uso masivo de Internet, los abusos que se han hecho de dicha tecnología también se han incrementado. En la actualidad, el mal uso que se le da a la información cubre aspectos tales como la propiedad intelectual, el acceso a la información libre o restringida, la censura, el uso de información de instituciones públicas, la confidencialidad, integridad, disponibilidad de los datos, y el flujo internacional de información, entre otros.

La seguridad informática es un conjunto de herramientas, procedimientos y estrategias que tienen como objetivo garantizar la integridad, disponibilidad y confidencialidad de la información de una entidad en un sistema. («Seguridad informática», 2019); se caracteriza por la protección de datos y de comunicaciones en una red asegurando, en la medida de lo posible, sus principios básicos los cuales son:

- Confidencialidad: Sólo los usuarios autorizados pueden acceder a nuestros recursos, datos e información.

- Integridad: Sólo los usuarios autorizados deben ser capaces de modificar los datos cuando sea necesario.

- Disponibilidad: Los datos deben estar disponibles para los usuarios cuando sea necesario.

- Autenticación: Estás realmente comunicándote con los que piensas que te estás comunicando.

La importancia de la seguridad informática radica en el hecho de que muchas de las acciones de nuestro día a día dependen de la seguridad informática a lo largo de toda la ruta que siguen nuestros datos (Universidad VIU, 2018). A pesar de que hoy en día la seguridad informática es un problema constante en todas las instituciones públicas y privadas, no todas ellas han tomado conciencia de esta problemática y no poseen una cultura de seguridad informática (Liñán Salinas, 2008).

El presente trabajo muestra un estudio realizado en entornos sociales usando técnicas de seguridad informáticas para obtener información no autorizada.
En el capítulo 1 se muestran los conceptos y definiciones. En el capítulo 2 se muestra el desarrollo del dispositivo. En el capítulo 3 se detallan los resultados obtenidos. Finalmente se mostrarán las conclusiones a las que se llegaron.

\section{Objetivos}

\section{Objetivo general}

- Hacer un estudio sobre el nivel de cultura en seguridad informática que posee una población usando técnicas de ingeniería social para intentar obtener información no autorizada.

\section{Objetivos específicos}

- Obtener información no autorizada de los posibles usuarios por medio de técnicas de seguridad informática.

- Concientizar a los usuarios sobre los dispositivos que conectamos a nuestra computadora y los peligros que representa.

- Analizar los resultados obtenidos.

\section{Conceptos y definiciones}

\section{Ingeniería social}

La ingeniería social es la manipulación psicológica de personas para que realicen cierta acción o den información sensible, algunos ejemplos de ello se ven en la vida cotidiana en:

- Llamadas de extorsión.

- Robos bancarios en cajeros automáticos.

- Robo de identidad mediante llamadas telefónicas.

En la ingeniería social para la informática se usa el estudio de las emociones, intereses y actividades de las personas. En general se usa el miedo, el engaño, el sentido de urgencia y la curiosidad.

Existen diferentes tipos de ingeniería social, estas son: 
- Basadas en personas.

- $\quad$ Impersonar (Imitar).

- Observación.

- $\quad$ Estudio de conductas.

- Basadas en computadoras.

- $\quad$ Engaños virales.

- Phishing.

- $\quad$ Software malicioso.

\section{Phishing}

No se sabe con exactitud el origen de su nombre, pero puede ser del dicho: "Si le das un pescado a un hombre, él comerá por un día, pero enséñale a pescar y tendrá para comer toda su vida", es decir, puede hace referencia a la palabra "fishing" que en español significa pescar.

Las técnicas de este tipo intentan obtener información sensible como: usuarios, contraseñas, tarjetas de crédito, entre otras. Es por eso que se le denominan: ataques de robo de identidad. Generalmente este tipo de técnicas se hacen con fines maliciosos y creando un escenario que parece legítimo.

\section{BadUSB}

Es un dispositivo presentado en Black Hat USA 2014 por Karsten Nphl, Sascha Klibler y Jakob Lell, el cual se hace pasar por un teclado o un ratón (Hack5, 2020).

Este falso USB al ser conectado al ordenador o dispositivo a atacar podrá ejecutar comandos en la terminal, instalar una puerta trasera para posteriormente acceder a ese ordenador, robar información y multitud de cosas más, programadas previamente por el atacante que pueden variar desde robar contraseñas almacenadas hasta ejecutar un virus. $\mathrm{Su}$ nombre comercial es Rubber Ducky, y físicamente parece una memoria USB inocente, pero que integra un micro ordenador con una SD (Secure Digital). Al conectarse a un dispositivo, es reconocido como HID (una interfaz humana) denominado comúnmente como teclado.
El sistema operativo cargará su driver de teclado USB y a partir de ahí, el dispositivo le mandará "pulsaciones" simuladas.

\section{Material y métodos}

\section{Material}

- Punto de acceso inalámbrico.

- Modem 4g.

- Computadora personal.

- Arduino ATTiny.

- Conexión a Internet.

- Acortador de enlaces.

- Servicio de almacenamiento en la nube.

\section{Métodos}

- Configurar el dispositivo de BadUSB usando un Arduino.

- Crear un punto de acceso falso para el robo de información usando el punto de acceso inalámbrico y el módem 4g.

- Moverse hacia un sitio con una gran afluencia de personas.

- Comunicar los resultados obtenidos e informar a los usuarios de su robo de información.

\section{Resultados}

\section{Resultados obtenidos del punto de acceso inalámbrico falso}

Con ayuda de herramientas informáticas (OffSec Services Limited, 2020), se creó un punto de acceso en el cual cuando un usuario al intentarse conectar a su red inalámbrica, el sistema pedía autenticarse usando su correo electrónico (ver Figura 1) para poder darle acceso a Internet. 


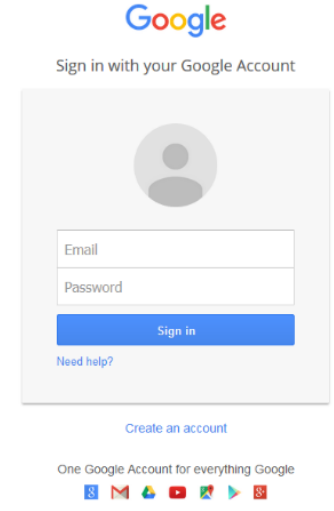

Figura 1 Sitio falso mostrado al usuario Fuente: elaboración propia [PowerPoint]

Una vez que el usuario ingrese su correo electrónico y contraseña, el sistema captura ambas (ver Figura 2) y le concede acceso a Internet.

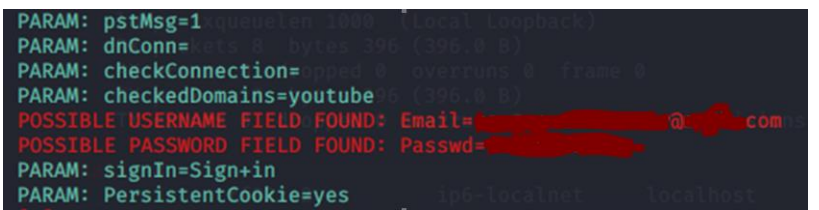

Figura 2 Sitio falso mostrado al usuario Fuente: elaboración propia [PowerPoint]

De lo anterior se obtuvo un total de 10 contraseñas robadas en 2 días de uso intermitente, los principales sitios en los cuales los usuarios estuvieron más expuestos fueron en centros comerciales. Cada vez que un usuario ingresaba sus datos en el sistema, se buscaba a la persona en cuestión y se confrontaba sobre lo que había ocurrido al intentar conectarse al dispositivo, su robo de información y posibles ataques adicionales a los que estaban expuestos, por lo tanto, se recomendó cambiar su contraseña tan pronto como fuera posible y evitar conectarse a puntos de acceso que pidan una previa verificación.

\section{Resultados obtenidos de la BadUSB}

Se desarrolló un código el cual permite al dispositivo actuar como un teclado convencional, gracias a esto, dentro del código se almacenan las instrucciones para poder descargar un archivo cualquiera desde Internet y posteriormente ejecutarlo automáticamente, en este caso se desarrolló un código el cual apagaba la computadora y no permitía encenderla nuevamente hasta eliminar el archivo descargado.
Una vez que se conecta el dispositivo, las instrucciones pre-programadas se ejecutan automáticamente, el primer bloque de sentencias tiene como finalidad descargar el archivo de apagado desde Internet.

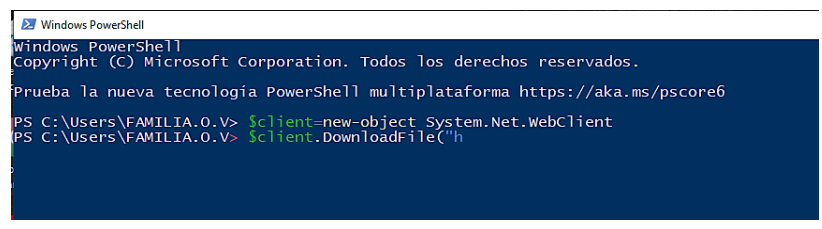

Figura 3 Secuencia de comandos ejecutados por la BadUSB para descargar el archive

Fuente: elaboración propia [PowerPoint]

Una vez que se descarga el archivo, se ejecuta un segundo bloque de comandos el cual permite instalar y ejecutar el archivo ejecutado en el sistema.

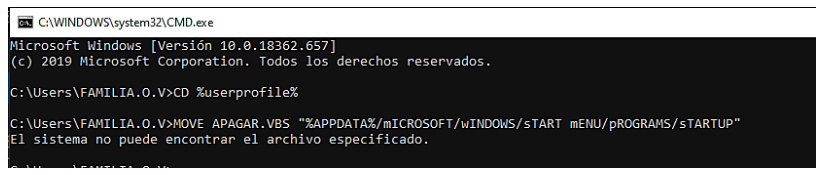

Figura 3 Secuencia de comandos para ejecutar e instalar un archivo

Fuente: elaboración propia [PowerPoint]

En este caso, el dispositivo fue dejado en lugares público a la espera de que alguien lo recogiera y conectara a su computadora. De un día de uso, se tuvo a 5 víctimas a las cuales se les explicó qué era lo que pasaba y se les removió el archivo mal intencionado de su computadora

\section{Conclusiones}

El estudio realizado usando técnicas de ingeniería social, fue de utilidad porque así los usuarios están concientes de los peligros que se pueden encontrar hoy en día.

La creación de un punto de acceso inalámbrico falso resultó útil para los usuarios habituales de internet, como adolescentes y adultos.

La investigación realizada sobre las BadUSB sirvió para poder tomar conciencia acerca de todos los dispositivos que conectamos a nuestra computadora, en la actualidad existen muchas maneras en las que podemos infectar nuestra computadora y no solo por medio de programas o archivos dañinos y en el cual es posible no solo hacer daño a una persona sino también a una empresa entera. 
Como sugerencia, es necesesario crear campañas que permitan a usuarios y empresas protegerse de este tipo de ataques informáticos. De esta forma, estarían concientes de los peligros que implican conectarse a redes inalámbricas desconocidas o poco confiables, así como el uso de dispotivos ajenos al usuario, con lo cual se evitaría ser víctima de un ataque de phishing o

\section{Referencias}

Hak5. (2020). USB Rubber Ducky. Recuperado el 28 de junio de 2020, de https://shop.hak5.org/products/usb-rubberducky-deluxe

Liñán Salinas, E. (2008). Plan de seguridad informática en la Escuela Universitaria de Postgrado de la Universidad Nacional Federico Villarreal. Repositorio institucional - WIENER. Recuperado de http://repositorio.uwiener.edu.pe/handle/123456 $789 / 99$

OffSec Services Limited. (2020). Kali Linux. Recuperado el 28 de junio de 2020, de https://www.kali.org/

Seguridad informática. (2019). Recuperado 25 de diciembre de 2019, de Significados website: https://www.significados.com/seguridadinformatica/

Universidad VIU. (s. f.). ¿Qué es la seguridad informática y cómo puede ayudarme? | VIU. Recuperado 25 de diciembre de 2019, de https://www.universidadviu.com/la-seguridadinformatica-puede-ayudarme/ 